\title{
ESTUDO SOBRE AS DIFERENTES TÉCNICAS DE SEXAGEM DE ESPERMATOZOIDES
}

\author{
Caroline Scott ${ }^{1}$ \\ Fabiana Ferreira Souza ${ }^{2}$ \\ Gabriele Barros Mothé ${ }^{2}$ \\ Viviana Helena Vallejo Aristizabal ${ }^{2}$ \\ José Antonio Dell Aqua Junior ${ }^{2}$
}

\begin{abstract}
RESUMO
O interesse na seleção de indivíduos de determinado sexo vem dos antigos gregos, mas o estudo sobre métodos eficazes desta seleção é relativamente novo. Saber qual será o sexo da futura progenie traz ao mercado um grande potencial para o melhoramento genético, A seleção do sexo contribui na bovinocultura para a otimização de animais do sexo desejado, em humanos evitando doenças ligadas ao sexo, ou mesmo na seleção de sexo em animais selvagens de cativeiro. Com o advento das biotecnologias, como a inseminação artificial e transferência de embriões, a sexagem começa a ter relevância no cenário atual e o custo benefício passa a ser significativo. Várias técnicas foram desenvolvidas visando a melhor préseleção de sexo, tal como a imuno separação, gradiente de densidade, e a citometria de fluxo que, no atual cenário mundial, é a técnica com os melhores resultados e a única que permite a comercialização do sêmen sexado. Os processos de sexagem ainda demandam muitos estudos, devido aos danos causados aos espermatozoides durante o processo de separação, comprometendo os resultados de fertilidade. Essa revisão de literatura vem como uma ferramenta para o entendimento do processo de sexagem e as técnicas utilizadas.
\end{abstract}

Palavras-chave: bovinos, citometria de fluxo, gradiente de densidade, imuno-sexagem, sêmen sexado.

\section{STUDY OF DIFFERENT SPERMATOZOA SEXING TECHNIQUES}

\begin{abstract}
The interest in sex selection of a particular individuals comes from the ancient greeks, but the study on effective methods of this selection is relatively new. Know future progeny sex brings to market great potential for genetic improvement. Sex selection contributes to cattle for animal optimization of desired sex, to human, preventing diseases sex-linked, or even sex selection of wild animals in captivity. With the biotechnologies advent such as artificial insemination and embryo transfer, sexing begins to have relevance in current scenario and benefit costs will be significant. Several techniques have been developed aiming the best preselection of sex, such as immuno separation, density gradient, and flow cytometry that in current world scenario is the technique with best results and only one that allows comercialization of sexed semen. Sexing processes still require many studies due to damage to sperm cells during the separation process, compromising fertility results. This literature review comes as a tool for understanding the sexing process and techniques used.
\end{abstract}

Key words: bovine, density gradient, flow cytometry, imuno-sexing, sex sorted sperm

\footnotetext{
${ }^{1}$ Discente do Programa de Doutorado no Departamento de Reprodução Animal e Radiologia Veterinária - FMVZ-UNESPBotucatu.

${ }^{2}$ Departamento de Reprodução Animal. Universidade Estadual Paulista. Correspondência.
} 


\title{
ESTUDIO SOBRE LAS DIFERENTES TÉCNICAS DE SEXAJE DE ESPERMATOZOIDES
}

\begin{abstract}
RESUMEN
El interés en la selección de individuos de un determinado sexo data de la antigua Grecia; sin embargo, estudios sobre métodos eficaces para la selección espermática son relativamente nuevos. Saber cuál será el sexo de la futura progenie trae al mercado un gran potencial para el mejoramiento genético. Esta selección del sexo es realizada con diversos enfoques; en bovinos para la optimización de animales de sexo deseado, en humanos evitando enfermedades ligadas al sexo y en animales salvajes en cautiverio en la selección del sexo. Con el adviento de las tecnologías como la inseminación artificial y la transferencia de embriones, el sexaje comenzó a tener relevancia en el escenario actual y el costo beneficio pasó a ser significativo. Varias técnicas han sido desarrolladas con el objetivo de mejorarla la pre-selección del sexo, la inmunoseparación, gradientes de densidad y citometria de flujo son algunas de ellas, sin embargo, en la actualidad, la citometria de flujo es la técnica con mejores resultados y la única que permite comercialización de semen sexado. No obstante, el proceso de sexaje aun demanda muchos estudios, debido a los daños ocasionados a los espermatozoides durante el proceso de separación, comprometiendo las tasas de la fertilidad. Esta revisión de literatura viene como una herramienta para el entendimiento del proceso de sexaje y las técnicas utilizadas.
\end{abstract}

Palablas clave: bovinos, citometria de flujo, gradientes de densidad, inmuno-sexage, semen sexado

\section{INTRODUÇÃO}

A venda de sêmen sexado vem crescendo no cenário da atual pecuária nacional, em 2011 já eram vendidas cerca de quase 12 milhões de doses de sêmen, e acredita-se que entre 600 a 800 mil doses são de espermatozoides sexados embora não há estatística para esse dado (1). A sexagem de espermatozoides visa à máxima produção com menor custo e a possibilidade de produzir doses inseminantes com espermatozoides portadores do cromossomo $\mathrm{X}$ ou $\mathrm{Y}$ especificamente de acordo com a necessidade de cada programa de melhoramento genético (2). Na bovinocultura o uso do sêmen sexado tem, entre seus vários benefícios, a produção de maior numero de machos para produção de touros reprodutores e estocagem de determinada unidade comercial e a produção de fêmeas para reposição ou aumento do rebanho (matrizes) (3).

Várias técnicas são descritas para a separação de espermatozoides X e Y, e todas estão em processo de adequação uma vez que ainda promovem danos irreparáveis aos espermatozoides e o seu DNA (2). De todas as técnicas já descritas, a citometria de fluxo é a única que permite a comercialização das doses sexadas devido aos $90 \%$ de acuidade já comprovada (4). A separação por gradiente de densidade é uma técnica promissora e assim como a citometria é baseada no maior peso do espermatozoide $\mathrm{X}$ dado pela maior quantidade de DNA (5). No que se refere à separação pelo método imunológico, é sabido que existem outras diferenças ainda que sutis entre os espermatozoides X e Y (6), porém essas diferenças podem ser essenciais no processo de separação espermática, como a presença do antígeno $\mathrm{H}$ Y, encontrado nos espermatozoides portadores do cromossomo Y (7). Vários estudos sobre proteínas ligadas ao sexo vêm sendo desenvolvidos a fim de que se produza um método imunológico para sexagem de espermatozoides conforme o interesse do criador. 
Os espermatozoides não podem perder seu poder fecundante e devem manter sua viabilidade após descongelação desta forma sêmen sexado deve ser compatível com a criopreservação mantendo o seu valor a um preço ajustado com a realidade do mercado. $\mathrm{O}$ aumento na procura pela inseminação artificial é que permite a sustentação de vendas de doses sexadas (2).

A tecnologia de sexagem de espermatozoides é relativamente nova, mas está em ascensão no mercado nacional e internacional. Dada a importância dessa biotecnologia para o desenvolvimento da pecuária nacional a presente revisão objetiva em um melhor conhecimento sobre a sexagem de espermatozoides bem como as técnicas utilizadas.

\section{Estratégias de separação dos espermatozoides X e Y}

Durante muitos séculos mitos e estratégias foram desenvolvidos com o objetivo de selecionar o sexo desejado, segundo Rezende (8) algumas estratégias utilizadas foram: pH do sistema genital feminino em que o pH mais ácido favorece o nascimento de fêmeas; nutrição da mãe antes e durante a gestação com o consumo de determinado alimento ou nutriente específico predispõe ao nascimento de macho ou fêmea, como por exemplo, o consumo de gordura saturada favorece o nascimento de machos, ácidos graxos poli-insaturados, ômega $3 \mathrm{e}$ ômega 6 e ácido ascórbico favorece o nascimento de fêmeas; concentração hormonal do macho e da fêmea no momento da cópula, a concentração de testosterona favorece o nascimento de machos. Momento da inseminação ou cópula em relação à ovulação: o nascimento de fêmeas pode ser favorecido quando a inseminação ou cópula ocorre próxima a ovulação. Essas entre outras estratégias foram utilizadas, porém não existem resultados palpáveis na literatura que comprovem esses métodos, tornando-os não eficazes no processo de pré-seleção do sexo.

Para a pré-seleção de sexo antes da concepção o único método eficaz é a separação de espermatozoides portadores do cromossomo $\mathrm{X}$ dos portadores do cromossomo $\mathrm{Y}$ (9). Para a bovinocultura essa seleção representa um grande potencial para o melhoramento genético e satisfação da demanda do mercado (10). Até a década de 80 não existia nenhum método efetivo da sexagem de espermatozóides (6).

Diversas especulações sobre as diferenças entre espermatozoides $\mathrm{X}$ e $\mathrm{Y}$ foram sugeridas, incluindo diferenças físicas como tamanho, peso, velocidade, densidade, motilidade, cargas elétricas superficiais, proteínas de superfície. Essas diferenças são tão sutis e praticamente impossíveis de mensurar, tornando os espermatozoides essencialmente idênticos nesse sentido (6).

Em 1910 aconteceu um grande marco com a descoberta dos cromossomos sexuais o que possibilitou a separação dos espermatozoides em X e Y (11). Inicialmente acreditava-se que o sexo era determinado apenas pelo cromossomo $\mathrm{X}$, onde as fêmeas eram classificadas como XX e os machos X0, somente em 1914 descobriu-se que o sexo masculino estava associado ao cromossomo $\mathrm{X}$ e um outro que foi denominado $\mathrm{Y}$ (12). Estudos mostram que os espermatozoides com cromossomo $\mathrm{X}$ tem mais DNA que os espermatozoides com cromossomo Y (5), essa diferença pode chegar a $4 \%$ variando com as espécies (13).

Muito se deve pensar economicamente quanto ao uso do sêmen sexado, observando se o potencial reprodutivo do touro está sendo maximizado com o uso do sêmen sexado, e o custo da implantação da tecnologia, ou seja, custo benefício ao comprar uma dose sexada (3) já que a dose sexada é mais cara que a dose convencional (14), e a única tecnologia aceita para comercialização é a citometria.

As técnicas de separação por sexo vêm ganhando mercado devido ao maior conhecimento da fisiologia do sêmen e sua contribuição genética ao embrião (15). Ressalta-se que para o uso do sêmen sexado devem ser descartados os rebanhos que não alcançaram $60 \%$ 
de concepção para o sêmen convencional. Doses sexadas têm seu uso recomendado somente para primeiro e segundo uso da novilha, não é aconselhável utilizar sêmen de alto valor em terceiro uso (13), uma vez que a fertilidade com sêmen sexado é menor (14).

Outro problema do sêmen sexado é que as células espermáticas ficam mais sensíveis ao processo de criopreservação pelas injurias causadas no processo de separação (16), como o estresse químico e físico sofrido no processo de sexagem usando o citômetro (17).

\section{Técnicas}

Vários estudos vêm sendo realizados na tentativa de descobrir a melhor forma de se obter crias com o sexo desejado. Para isso algumas tecnologias têm sido testadas nessa área incluindo a utilização de anticorpos específicos do gênero, centrifugação em gradiente de densidade, e citometria de fluxo (18). Estas técnicas ainda se encontram em processo de aperfeiçoamento para se adequarem à indústria do sêmen, uma vez que todas causam danos aos espermatozoides, ao seu DNA, a motilidade, assim como a cinética espermática comprometendo o processo de fertilização $(2,19)$.

\section{Centrifugação em gradiente de densidade}

A centrifugação em gradiente de densidade é considerada uma metodologia simples (15). O processo se baseia na diferença de densidade entre os espermatozoides X e Y, uma vez que os espermatozoides $X$ possuem mais DNA que os espermatozoides $Y$ (5). Em um trabalho foram testados 13 diferentes gradientes de densidade, o sêmen foi depositado sobre os gradientes em um tubo que foi centrifugado em velocidade e tempo determinado segundo o protocolo. Após a centrifugação os espermatozoides foram separados em duas frações, o sobrenadante foi descartado e o sedimento das duas frações foi aspirado nos gradientes de oito e 12 camadas. Os espermatozoides recuperados foram $25 \%$ e $75 \%$ de Y e X, respectivamente (20).

Em um estudo a diferença entre o uso dos gradientes de albumina, PureSperm e albumina conjugada com PureSperm para separação dos espermatozoides X e Y não apresentaram resultados significativos (21). O uso de um gradiente de densidade de sacarose também mostrou resultados sem diferenças estatísticas para a separação do sexo, entretanto os autores afirmam que esse gradiente é uma ótima ferramenta e de baixo custo para esse fim, porém mais estudos são necessários (22). Tucker e Jansen (15) estudaram os métodos de centrifugação por gradiente de densidade e afirmaram que a centrifugação é o método mais eficiente, e que existem alternativas ao uso do Percoll ainda que com alto custo.

Sucessivas centrifugações causam danos às células espermáticas, desta forma, a diminuição no numero de centrifugações diminui as injurias causadas aos espermatozoides $(23,24)$. Foi testado um novo gradiente composto de soluções isotônicas que permite que em uma única centrifugação haja separação de impurezas dos espermatozoides viáveis e esses ainda serem separados em $\mathrm{X}$ e $\mathrm{Y}$, Uma pesquisa desenvolvida com separação de espermatozoides $\mathrm{X}$ e $\mathrm{Y}$ com gradiente de densidade Percoll revelou resultados positivos quanto ao uso da técnica uma vez que após a centrifugação houve a separação dos espermatozoides por sexo com acuidade de $75 \%$ e $25 \%$ de taxa de recuperação de espermatozoides, apesar de ser uma técnica com menor recuperação comparada a citometria de fluxo o gradiente de densidade é um processo mais rápido e com maior porcentagem de motilidade (20).

\section{Citometria de fluxo}

Scott C, Souza FF, Mothé GB, Aristizabal VHV, Del'Aqua Junior JD. Estudo sobre as diferentes técnicas de sexagem de espermatozoides. Vet. e Zootec. 2018 mar.; 25(1): 021-029. 
A citometria de fluxo é um método capaz de estimar conteúdo de DNA do espermatozoide e separá-lo em X ou Y. É uma técnica eficaz em várias espécies de mamíferos para sêmen fresco e criopreservado (25).

Inicialmente foi usada para muitos propósitos especialmente para diagnóstico de câncer, uma vez que o DNA poderia ser um indicador sensitivo de eventos mutagênicos. $O$ uso na sexagem de espermatozoides é mais recente (26) e se tornou o único método comprovado para separação por sexo. Foi usado pela primeira vez na década de 80 para esse fim, mas com pouco sucesso pois havia separação dos espermatozoides $\mathrm{X}$ e $\mathrm{Y}$, porém promovia a morte celular e, por este motivo, um novo sistema foi desenvolvido, modificando o citômetro em alguns aspectos levando ao sucesso da técnica com poucos danos aos espermatozoides $(18,27)$. Após a década de 80 ocorreu um grande avanço na citometria e várias gestações do sexo determinado em espécies diferentes foram obtidas, desde então vem sendo usada no cenário atual com bastante sucesso (13).

Partindo do principio que as células X e Y possuem conteúdo de DNA total diferentes, variando na média de 3 a 4\% entre as espécies, no touro varia de 3,7 - 4,44\% (4) O citômetro de fluxo ao ser calibrado consegue separar as células com mais de $90 \%$ de pureza, pois detecta essas diferenças $(4,13)$

Garner (28) cita que em diferentes mamíferos além da diferença do conteúdo de DNA existe a diferença na capacidade de orientação dos gametas no momento da classificação pelo citômetro.Os espermatozoides com cabeça mais achatada e oval tendem a ser mais hidrodinâmicos que aqueles com cabeça mais arredondada ou angular, e os espermatozoides de touros são os mais fáceis de serem sexados pelo citômetro, pois dentre as espécies estudadas são os que possuem a maior área de cabeça. De acordo com o descrito por Johnson e Welch (26), não há diferenças na velocidade de deslocamento entre os espermatozoides X e Y de bovinos respondendo a uma controvérsia que existia há mais de 25 anos a esse respeito quando estudos foram feitos com espermatozoides de humanos.

A separação se faz por meio do uso de uma sonda fluorescente com especificidade para DNA, e após essa marcação a separação ocorre de acordo com a intensidade da fluorescência (26). Para a separação por citometria de fluxo a sonda utilizada é o Hoechst 33342 penetra na célula espermática íntegra e se liga ao DNA, como o espermatozoide $\mathrm{X}$ possui uma maior porcentagem de DNA em relação ao Y é mais marcado, assim, quando são excitadas pelo laser, emitem uma maior intensidade de fluorescência que os espermatozoides $Y$, essa diferença é detectada pelos filtros fotomultiplicadores e analisada pelo computador (29).

Os espermatozoides são analisados via computador e os com o cromossomo $\mathrm{X}$ recebem uma carga positiva, os com cromossomo Y recebem uma carga negativa, os indistinguíveis ou danificados não recebem nenhuma carga. A gotícula que sai em alta velocidade pelo bico do citômetro passa por um campo elétrico e os espermatozoides são atraídos, os X com carga positiva são atraídos pelo campo negativo, e os Y com carga negativa são atraídos pelo campo positivo, os que não possuem carga prosseguem sem serem atraídos para campo algum, dessa forma são produzidos três fluxos que são recolhidos por tubos coletores (29).

Apesar de ser a melhor técnica desenvolvida até hoje, passam por segundo pelo citômetro de fluxo cerca de 3 a 5 mil espermatozoides, sendo necessárias 1,3 horas para separar sêmen suficiente para uma palheta de 20 milhões, além disso, apenas cerca de 30\% das células são orientadas, ou seja, somente $15 \%$ de cada sexo. Devido a esse lento processo a comercialização só é possível em uma concentração menor por palheta (dois milhões), somado a isso tem o alto custo do citômetro e a necessidade de profissionais qualificados, tornando o custo do sêmen sexado elevado. Além desses fatores, esses espermatozoides tem viabilidade comprometida, dessa forma recomenda-se que esse sêmen seja utilizado em rebanhos bem manejado e novilhas férteis com alta taxa de concepção $(13,30)$.

Scott C, Souza FF, Mothé GB, Aristizabal VHV, Del'Aqua Junior JD. Estudo sobre as diferentes técnicas de sexagem de espermatozoides. Vet. e Zootec. 2018 mar.; 25(1): 021-029. 


\section{Utilização de anticorpos específicos do gênero}

Pela identificação de uma proteína sexo-específica na membrana plasmática dos espermatozoides $\mathrm{X}$ e $\mathrm{Y}$ e a partir do desenvolvimento de um ou mais anticorpos antiproteína $\mathrm{X}$ ou antiproteína $\mathrm{Y}$ foi possível criar um método imunológico de sexagem de espermatozoides, $(31,32)$. Esse método possui várias vantagens como o baixo custo no processamento, técnica menos invasiva ao espermatozoide e não oferece limitações na produção espermática (33).

Várias publicações e patentes sugerem que é possível a sexagem de espermatozoides pela produção de anticorpos, que determinam proteínas de membrana sexo específicas. Ainda, que os estudos sejam iniciais os resultados já obtidos foram conclusivos. Foi detectada a expressão de 14 proteínas diferentes entre X e Y, essas proteínas afetam energia, metabolismo estresse, resistência, composição do citoesqueleto, entre outros fatores nos espermatozoides. (34)

O antígeno de membrana H-Y foi descrito em 1955 por Eichwald e Silmser ao verificarem que havia rejeição quando pele de rato macho era transplantado para uma fêmea, entretanto quando o procedimento foi realizado ao contrário fêmea/macho a rejeição não era observada. Nos estudos de Bradley et al. (35) foi detectada a expressão do antígeno H-Y na membrana plasmática de espermatozoides de carneiros por várias abordagens diferentes. No teste de ELISA foi observado que o antígeno $\mathrm{H}-\mathrm{Y}$ é muito sensível e com boa especificidade, a análise de Western blot revelou que a membrana plasmática flagelar contém uma proteína sexo-especifica masculina com peso molecular de aproximadamente $25.000 \mathrm{kDa}$.

Em um trabalho com suínos utilizando anticorpos policlonais observou a elevada afinidade com os espermatozoides o que levou a uma cessação da motilidade, a maioria dos espermatozoides não móveis tinham o cromossomo $\mathrm{Y}$, concluindo que o uso de antígenos policlonais contra H-Y pode ser um meio simples e barato de sexagem uma vez que a redução da motilidade dos espermatozoides reduz a habilidade de fertilização (36).

Pesquisadores desenvolveram anticorpos policlonais em ovinos, e relataram que ocorreu somente no macho uma reação contra uma proteína originaria de tecido (32). Blecher, (37) registrou em patente (US 5,840,504; 24/11/1998) as proteínas sexo especificas denominadas SSP (Sex Specific Protein) e o desenvolvimento de um método na sexagem imunológica. O método se baseia na incubação de espermatozoides bovinos com anticorpos antiproteína $\mathrm{X}$ previamente identificados, isolados e purificados por cromatografia de coluna. Após a incubação houve $50 \%$ de aglutinação dos espermatozoides, as que não sofreram aglutinação produziram in vitro $92 \%$ embriões do sexo masculino confirmado pela sexagem por citogenética. Não foi relatado se a incubação de espermatozoides com anticorpos antiproteínas específicas do sexo masculino também promoveu o desvio da proporção sexual em favor do sexo feminino.

Existem trabalhos e patentes que discutem o uso de anticorpos sexo específicos, mas nenhum deles ainda mostrou um resultado consistente (38). No que se refere à utilização prática da seleção do sexo por métodos imunológicos permanece a limitação da necessidade de mais investigações, utilizando técnicas de identificação de proteínas mais sensíveis, a fim de produzir um anticorpo específico do espermatozoide $\mathrm{X}$ ou $\mathrm{Y}$.

\section{CONSIDERAÇÕES FINAIS}

A sexagem de espermatozoides vem ganhando grande relevância no atual mercado da bovinocultura, diversas técnicas vêm sendo desenvolvidas a fim de que maior quantidade de espermatozoides possam ser sexados em menor tempo. 
Das técnicas conhecidas a única que permite a comercialização das doses sexadas é a citometria de fluxo que apesar de propiciar $90 \%$ de separação ainda existem $10 \%$ de erro o que torna necessários mais estudos envolvendo a técnica. A centrifugação por gradiente de densidade apresenta resultados promissores e apesar da motilidade final ser boa, ainda não tem uma acurácia relevante para o mercado. $\mathrm{O}$ método de sexagem por anticorpos está apenas no início, e apesar dos vários estudos no mundo todo a esse respeito ainda existem questionamentos sobre a viabilidade da técnica.

O conhecimento que já existe a respeito do assunto mostra a grande importância da sexagem de espermatozoides, tanto para doses frescas como doses criopreservadas, levando a uma expansão do mercado e das biotécnicas utilizadas na reprodução animal.

\section{AGRADECIMENTO}

Entidade financiadora FAPESP.

\section{REFERÊNCIAS}

1. MilkPoint. ASBIA comemora forte crescimento em 2011 [Internet]. Piracicaba: MilkPoint; 2016 [cited 2011 Sept 15]. Available from: http://www.milkpoint.com.br/cadeia-doleite/giro-lacteo/asbia-comemora-forte-crescimento-em-2011-77880n.aspx.

2. Lima VFMH. Avanços metodológicos na seleção do sexo de espermatozoides bovinos para utilização no melhoramento genético e na produção animal. Rev Bras Zootec. 2007;36:219-28.

3. Pace MM. Implications of Sexed Semen on the Beef Industry. In: Proceedings of 39th Annual Florida Beef Cattle Short Course; 1990; Gainesville, FL. Gainesville: University of Florida; 1990. p.238.

4. Sharpe JC, Evans KM. Advances in flow cytometry for sperm sexing. Theriogenology. 2009;71:4-10.

5. Sumner AT, Robinson JA. A difference in dry mass between the heads of X-and Ybearing human spermatozoa. J Reprod Fertil. 1976;48:9-15.

6. Garner DL, Seidel Jr GE. History of commercializing sexed semen for cattle. Theriogenology. 2008;69:886-95.

7. Eichwald EJ, Silmser CR. Untitled communication. Transplant Bull. 1955;2:148-9.

8. Rezende VM. Sexagem de espermatozoides bovinos por centrifugação em gradiente de densidade contínuo de percoll e optiprep [dissertação]. São Paulo: Universidade Estadual Paulista; 2007.

9. Maxwell WMC, Evans G, Hollinshead FK, Bathgate RDE, Graaf SP, Eriksson BM, et al. Integration of sperm sexing technology into the ART toolbox. Anim Reprod Sci. 2004;82:79-95.

10. Parati K, Bongioni G, Aleandri R, Galli A. Sex ratio determination in bovine semen: a new approach by quantitative real time PCR. Theriogenology. 2006;66:2202-9. 
11. Seidel Jr GE, Garner DL. Current status of sexing mammalian spermatozoa. J Reprod Fertil. 2002;124:733-43.

12. Medalha AG. Sêmen sexado [monografia]. Campo Grande: Universidade Federal do Mato Grosso do Sul; 2008.

13. De Jarnette M. Sêmen sexado: uma realidade. 2012 [cited 2012 Jun 24]. Available from: http://www.semeia.com.br/site/artigo.php?ID=94\&IDC=3\&PHPSESSID=7779520d 1346 c3e53f0e3cb2030804a8.

14. De Vries A, Overton M, Fetrow J, Leslie K, Eicker S, Rogers G. Exploring the impact of sexed semen on the structure of the dairy industry. J Dairy Sci. 2008;91:847-56.

15. Tucker K, Jansen CAM. Sperm separation techniques: comparison and evaluation of gradient products. In: Proceedings of 2nd International Workshop for Embryologists: Troubleshooting Activities in the ART lab; 2002.

16. Hollinshead FK, Gillan L, O’Brien JK, Evans G, Maxwel LWM. In vitro and in vivo assessment of functional capacity of flow cytometrically sorted ram spermatozoa after freezing and thawing. Reprod Fertil Dev. 2003;15:351-9.

17. Seidel Jr GE. Economics of selecting for sex: the most important genetic trait. Theriogenology. 2003;59:585-98.

18. Fetrow J, Overton M, Eicker S. Sexed Semen: economics of a new technology. In: Western Dairy Management Conference; 2007; Reno. Reno: Western Dairy Management Conference; 2007. p.1-24.

19. Carvalho JO, Sartori R, Lemes AP, Mourão GB, Dode MAN. Cinética de espermatozoides criopreservados de bovinos após sexagem por citometria de fluxo. Pesqui Agropecu Bras. 2009;44:1346-51.

20. Lima VFMH, Moreira Filho CA, Lucio AC, Resende MV. Sexagem de espermatozoides bovinos por centrifugação em gradiente descontínuo de densidade de Percoll. Rev Bras Zootec. 2011;40:1680-5.

21. Esmaeilpour T, Elyasi L, Bahmanpour S, Ghannadi A, Monabbati A, Dehghani F, et al. Effect of combined density gradient centrifugation on X- and Y- sperm separation and chromatin integrity. Iran J Reprod Med. 2012;10:435-40.

22. Kanesharatnam N, Eswaramohan T, Balasubramaniam K. A Preliminary study for sperm sexing by using sucrose density gradients in jersey bull at artificial insemination centre at thirunelvely (northern province of Sri Lanka). In: Proceedings of International Conference on Bioscience, Biochemistry and Bioinformatics; 2012; Singapura. Singapura: ICBBB; 2012. p.37-40.

3. Lima VFMH, Moreira Filho CA, Ramalho MFPDT. Processo de seleção do sexo de espermatozoides mamíferos e métodos de controle de qualidade de doses de sêmen sexado congelado. BR PI 0300604-2. 17 Jun 2003. 
24. Lima VFMH. Espermatozoide sexado bovino: quando utilizá-lo? Acta Sci Vet. 2006;34:213-24.

25. Pinkel D, Garner ADL, Gledhill BL, Lake S, Stephenson D, Johnson LA. Flow cytometric determination of the proportions of $\mathrm{x}$ - and $\mathrm{y}$-chromosome-bearing sperm in samples of purportedly separated bull sperm. J Anim Sci. 1985;60:1303-7.

26. Johnson LA, Welch GR. Sex preselection: high-speed flow cytometric sorting of $x$ and $y$ sperm for maximum efficiency. Theriogenology. 1999;52:1323-41.

27. Johnson LA, Pinkel, D. Modification of a laser-based flow cytometer for high-resolution DNA analysis of mammalian spermatozoa. Cytometry. 1986;7:268-73.

28. Garner DL. Flow cytometric sexing of mammalian sperm. Theriogenology. 2006;65:94357.

29. Seidel Jr GE. Overview of sexing sperm. Theriogenology. 2007;68:443-6.

30. Bondan JA. Sêmen sexado, finalmente é uma realidade? [Internet]. 2012 [cited 2012 Apr $10]$. Available from: http://www.semeia.com.br/site/artigo.php?ID=60\&IDC=1\&PHPSESSID=8b33be216ebb $66096488 \mathrm{ec} 39 \mathrm{a} 6 \mathrm{ba5014.}$

31. Hendriksen PJM. Do $\mathrm{X}$ and $\mathrm{Y}$ spermatozoa differ in proteins? Theriogenology. 1999;52:1295-308.

32. Van Tilburg MF, Machado OLT, Silva JFS, Matta CGF, Fagundes B, Matta MFR. Identificação de antígeno macho-específico de ovino. Rev Port Cienc Vet. 2006;101:2313.

33. Kupradit C, Ketudat Cairns M. The extraction and purification of boar sperm surface protein. J Sci Technol. 2009;16:245-351.

34. Chen X, Zhu H, Wu C, Han W, Hao H, Zhao X, et al. Identification of differentially expressed proteins between bull X and Y spermatozoa. J Proteomics. 2012;77:59-67.

35. Bradley MP, Forrester IT, Heslop BF. Identification of a male-specific (H-Y) antigen on the flagellar plasma membrane of ram epididymal spermatozoa. Hum Genet. 1987;75:362-7.

36. Mohammadi AA, Tetro JA, Filion LG. Epitope selection to male specific antigens for sex selection in swine. J Reprod Immunol. 2011;89:46-54.

37. Blecher SR, Howie SL, Detmar J, Blahut LM. A new approach to immunological sexing of sperm. Theriogenology. 1999;52:1309-21.

38. Blecher SR. Method for separating sex specific molecules and non-sex specific molecules. United States patent US 5,840,504. 1998 Nov 24.

Recebido em: Aceito em:

Scott C, Souza FF, Mothé GB, Aristizabal VHV, Del'Aqua Junior JD. Estudo sobre as diferentes técnicas de sexagem de espermatozoides. Vet. e Zootec. 2018 mar.; 25(1): 021-029. 